Article

\title{
Reactivity of Copper Electrodes towards Functional Groups and Small Molecules in the Context of $\mathrm{CO}_{2}$ Electro-Reductions
}

\author{
Bernhard Schmid ${ }^{1,2}$, Christian Reller ${ }^{1}$, Sebastian S. Neubauer ${ }^{1,3}$, Maximilian Fleischer ${ }^{1}$, \\ Romano Dorta ${ }^{2}$ and Guenter Schmid ${ }^{1, *}$ \\ 1 Siemens AG, Corporate Technoloy, Research for Energy \& Electronics, Guenther Scharowsky Strasse 1, \\ 91058 Erlangen, Germany; schmid.bernhard@siemens.com (B.S.); christian.reller@siemens.com (C.R.); \\ neubauer_sebastian@t-online.de (S.S.N.); maximilian.fleischer@siemens.com (M.F.) \\ 2 Lehrstuhl für Anorganische und Allgemeine Chemie, Friedrich Alexander Universität Erlangen-Nürnberg, \\ Egerlandstraße 1, 91058 Erlangen, Germany; romano.dorta@fau.de \\ 3 Lehrstuhl für Physikalische Chemie I, Friedrich-Alexander-Universität Erlangen Nürnberg, \\ Egerlandstraße 1, 91058 Erlangen, Germany \\ * Correspondence: guenter.schmid@siemens.com; Tel.: +49-913-173-2109
}

Academic Editor: Rajendra S. Ghadwal

Received: 28 March 2017; Accepted: 4 May 2017; Published: 18 May 2017

\begin{abstract}
The direct electro-reduction of $\mathrm{CO}_{2}$ to functional molecules like ethene is a highly desirable variant of $\mathrm{CO}_{2}$ utilization. The formation of, for example, ethene from $\mathrm{CO}_{2}$ is a multistep electrochemical process going through various intermediates. As these intermediates are organic species, the $\mathrm{CO}_{2}$ reducing electro-catalyst has to be competent for a variety of organic functional group transformations to yield the final product. In this work, the activity of an in situ-grown nano-structured copper catalyst towards a variety of organic functional group conversions was studied. The model reagents were selected from the product spectrum of actual $\mathrm{CO}_{2}$ reduction reaction $\left(\mathrm{CO}_{2} \mathrm{RR}\right)$ experiments and from proposals in the literature. The $\mathrm{CO}_{2}$ bulk electrolysis benchmark was conducted at $170 \mathrm{mAcm}^{-2}$ current density with up to $43 \%$ Faradaic Efficiency (FE) for ethene and $23 \% \mathrm{FE}$ for ethanol simultaneously. To assure relevance for application-oriented conditions, the reactivity screening was conducted at elevated current densities and, thus, overpotentials. The found reactivity pattern was then also transferred to the CO reduction reaction (CORR) under benchmark conditions yielding additional insights. The results suggest that at high current density/high overpotential conditions, also other ethene formation pathways apart from acetaldehyde reduction such as $\mathrm{CH}_{2}$ dimerization are present. A new suggestion for a high current density mechanism will be presented, which is in agreement with the experimental observations and the found activity pattern of copper cathodes toward organic functional group conversion.
\end{abstract}

Keywords: $\mathrm{CO}_{2}$ electro-reduction; electro-catalytic mechanism; carbene carbonylation; electrohydrogenation

\section{Introduction}

During the last few decades, researchers began tackling the problem of fossil fuel usage. The main task is the establishment of a closed carbon cycle and the implementation of renewable energy sources. Characteristic for the latter one are seasonal and weather-induced fluctuations [1,2]. To compensate for such intermittency, the installation of large overcapacities is necessary, which yet will produce stranded energy under optimal weather conditions. $\mathrm{CO}_{2}$ electro-reduction is a feasible storage pathway for this stranded energy, which, at the same time, recycles emitted carbon, thus creating a closed carbon cycle $[3,4]$. These considerations have led to a vast increase of research efforts in $\mathrm{CO}_{2}$ electro-reduction [5]. In this 
context, copper seems to be a unique element that unifies the properties of a high $\mathrm{H}_{2}$-overpotential enabling operation in low-cost aqueous electrolytes, comparably low $\mathrm{CO}_{2}$-reduction overpotentials and being the only element featuring $\mathrm{C}-\mathrm{C}-$ bond formation and formation of products originating from transfer of more than two electrons [6,7].

Products like ethene are of particular interest as their economic value as chemical feedstock exceeds their heating value by up to more than one order of magnitude (example in Supplementary Material (SM)). Pioneering work in $\mathrm{CO}_{2}$ reduction was done by Hori [8] and Paik [9] on mercury electrodes. Copper-catalyzed $\mathrm{CO}_{2}$ reduction to hydrocarbons was first reported by Hori in 1985 [10]. In the following decades, publications using copper electrodes [11-17], copper oxide electrodes [18-21], copper-containing perovskites [22], oxide-supported copper catalysts [23], halide-derived copper catalysts [24-27], copper-based alloys [28], copper-based metal-organic frameworks [29], molecular copper complexes [30], as well as alternative systems [5,31-36] vastly increased. Also pyridine-based co-catalysis known from Pd electrodes [37] could recently be transferred to copper-based systems [38]. Only recently, NiGa alloys have also been reported to produce trace amounts of ethene [39] and cobalt-proto-porphyrins producing methane [40].

Systematic catalyst development in this area requires a reliable model for the relationships between the products, intermediates and the catalyst properties. Understanding the mechanism is therefore a key to $\mathrm{CO}_{2}$ electro-reduction as an applicable technology.

Attempts tackling the mechanism of $\mathrm{CO}_{2}$ reduction by means of DFT-calculations [41-47], in operando spectroscopy [48-50] and surface science methods [21,50,51] are numerous. Yet, there is only one limited attempt of studying the reactivity of certain model compounds [52]. The research in this area is mainly focused on ethene, ethanol and formate and there is still lack of a general scheme covering all products. In this study, a more general approach to the mechanism was chosen. During the reduction of $\mathrm{CO}_{2}$ to $\mathrm{C} 2$ or even $\mathrm{C} 3$ hydrocarbons and mono-oxygenates, the reaction goes through several electron transfer steps and numerous intermediates. These intermediates, however, have in common that they are organic or copper-organic species. The functional groups in these species are converted by electrochemical reduction into others in each step. Thus, studying the activity of a copper cathode catalyst towards reductive conversions of organic functional groups is a feasible way of tackling the mechanism. This method will elucidate which reactions are feasible to get from one intermediate to another, without limiting the understanding to a particular product. By this attempt, guidelines for mechanistic pathways can be obtained. Therefore, we conducted a screening at previously found optimum conditions by variation of 22 reactants.

It should be noted that the entire study was deliberately executed far from reaction onsets at potentials $<-1 \mathrm{~V}$ vs. Reversible Hydrogen Electrode (RHE), as they occur at application relevant current densities. In contrast, the majority of mechanistic studies is conducted at close-to-onset potentials and therefore does not reach application relevant current densities. These conditions are often chosen to avoid non-equilibrium conditions and the corresponding local gradients, such as high $\mathrm{pH}$ values, concentration gradients and high overpotentials. In this study, these conditions are regarded as an inevitable aspect of applied $\mathrm{CO}_{2} \mathrm{RR}$ and it is intended to reevaluate concepts found for close-to-onset conditions under high current density conditions.

\section{Results and Discussion}

\section{1. $\mathrm{CO}_{2}$ Bulk Electrolysis Benchmark}

We recently introduced a nano-scale copper dendrite electro-catalyst, which on a carbon gas diffusion layer (GDL) is capable of achieving over 50\% Faradaic Efficiency (FE) for ethene at $170 \mathrm{mAcm}^{-2}[53,54]$. For this screening, this was the model catalyst of choice.

The catalyst is grown in situ from an acidic $6.4 \mathrm{mM} \mathrm{CuSO}_{4}$ solution. The unique feature of this catalyst is its fine nano-scale dendrite structure, which creates many high index planes that are known 
to be beneficial for ethanol evolution [55]. This structure is created by the templating effect of hydrogen bubbles, which are present due to the high current density and the low initial $\mathrm{pH}$ [56].

To be able to properly reflect the product scope of actual $\mathrm{CO}_{2} \mathrm{RR}$ in the choice of the model reagents, the liquid phase products were also analyzed in the same $10 \mathrm{~min}$ time grid as the gaseous products. The FEs of all major gaseous and liquid products are compiled in Figure 1.

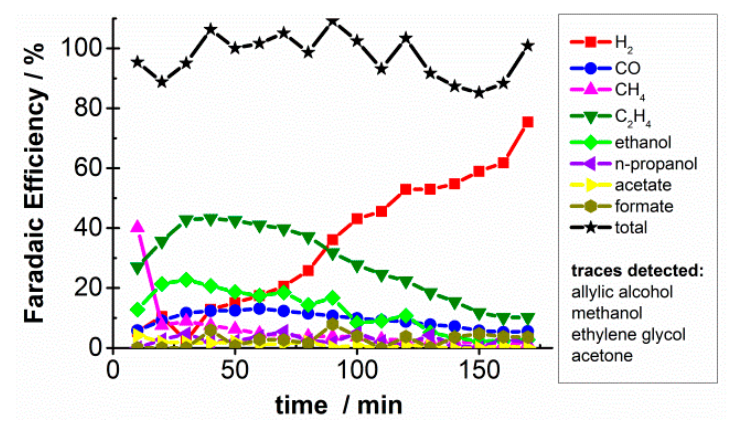

Figure 1. Faradaic Efficiency (FE) vs. time for major products of $\mathrm{CO}_{2}$ bulk electrolysis at $170 \mathrm{mAcm}^{-2}$.

The main liquid phase product was ethanol. Besides, also $n$-propanol, acetate, ethylene glycol and formate (FE $2 \%-5 \%$ ) and traces of allyl alcohol, methanol and acetone ( $\mathrm{FE}<1 \%$ ), were quantified.

Noteworthy, the liquid analysis revealed an excellent performance of the catalyst also for ethanol formation in addition to the ethene performance. The FE for ethanol reached $23 \%$ after $30 \mathrm{~min}$ of electrolysis, which equals a partial current density of $39.1 \mathrm{mAcm}^{-2}$. This is among the highest reported values for ethanol. The Kenis group has reported an even higher value of $53 \mathrm{mAcm}^{-2}$, yet in an open system with a non-cycled $\mathrm{KOH}$ electrolyte at $\mathrm{pH}=14$ [57]. In our closed electrolyte cycle, which is closer to a continuously operable setup, using $\mathrm{KBr}$ and $\mathrm{KHCO}_{3}$, the $\mathrm{pH}$ sets to $\sim$ due to the $\mathrm{CO}_{2} / \mathrm{HCO}_{3}$-buffer. Figure S35 (SM) gives evidence for this buffer along with working electrode (WE) potential and voltage data for the experiments.

In terms of functional groups, the products spectrum of $\mathrm{CO}_{2} \mathrm{RR}$ features alkanes, electron-rich alkenes, carboxylates, terminal alcohols and ketones. The model reagents were chosen accordingly. On the other hand, the product scope lacks aldehydes, secondary alcohols, electron-deficient alkenes and alkynes. However, their absence may be explained either by lack of a formation pathway or by very high reactivity. Therefore, these classes are actually candidates for highly reactive intermediates. In addition, suggestions from the literature as glyoxal (20) or ethylene glycol (21) were also evaluated.

\subsection{Model Reagent Screening}

The screening was conducted on freshly prepared in situ-grown model catalyst on a solid copper support as also described in the previous work [54]. This method is more feasible for liquid or solid model reagents and allowed more precise measurements due to the reduced electrolyte volumes. The reagents are tested by addition of a sub-stoichometric amount (with respect to the total charge) after $10 \mathrm{~min}$ of catalyst deposition time. The galvanostatic bulk electrolysis strategy has the advantage that also reactions with lower onset potentials and with low Faradaic Efficiencies can be observed. Experiments with authentic products/intermediates are depicted in the suggested mechanism in Scheme 1. Additional model reactions are illustrated in Scheme 2.

Table S2 in the Supplementary Materials (SM) compiles important reactivity data obtained from each reactant. The given potentials are average values for the WE potential $50 \mathrm{~s}$ after addition of a reacting reactant. Those substrates usually cause a spontaneous distinctive rise of the potential, while it remains practically constant for inert or poorly reacting substrates. Examples of working electrode potential curves for both reacting and inert substrates are compiled in Figure S27 (SM). We also identified the subsiding of hydrogen evolution as a descriptive feature for the feasibility of a transformation. Also, $\mathrm{CO}_{2} \mathrm{RR}$ itself is a competing process to the hydrogen evolution reaction 
(HER). Thus, reactions that cannot compete with the HER are unlikely to participate in the mechanism. Notable changes in the electrolyte conductivity due to small volumes and the Nafion ${ }^{\circledR}$ separator lead to corruption of the IR-drop compensation. Table S2 (SM) therefore shows uncompensated values. Additional Spectra, GC data and exemplary electrical parameters are compiled in the Supplementary Materials (SM).

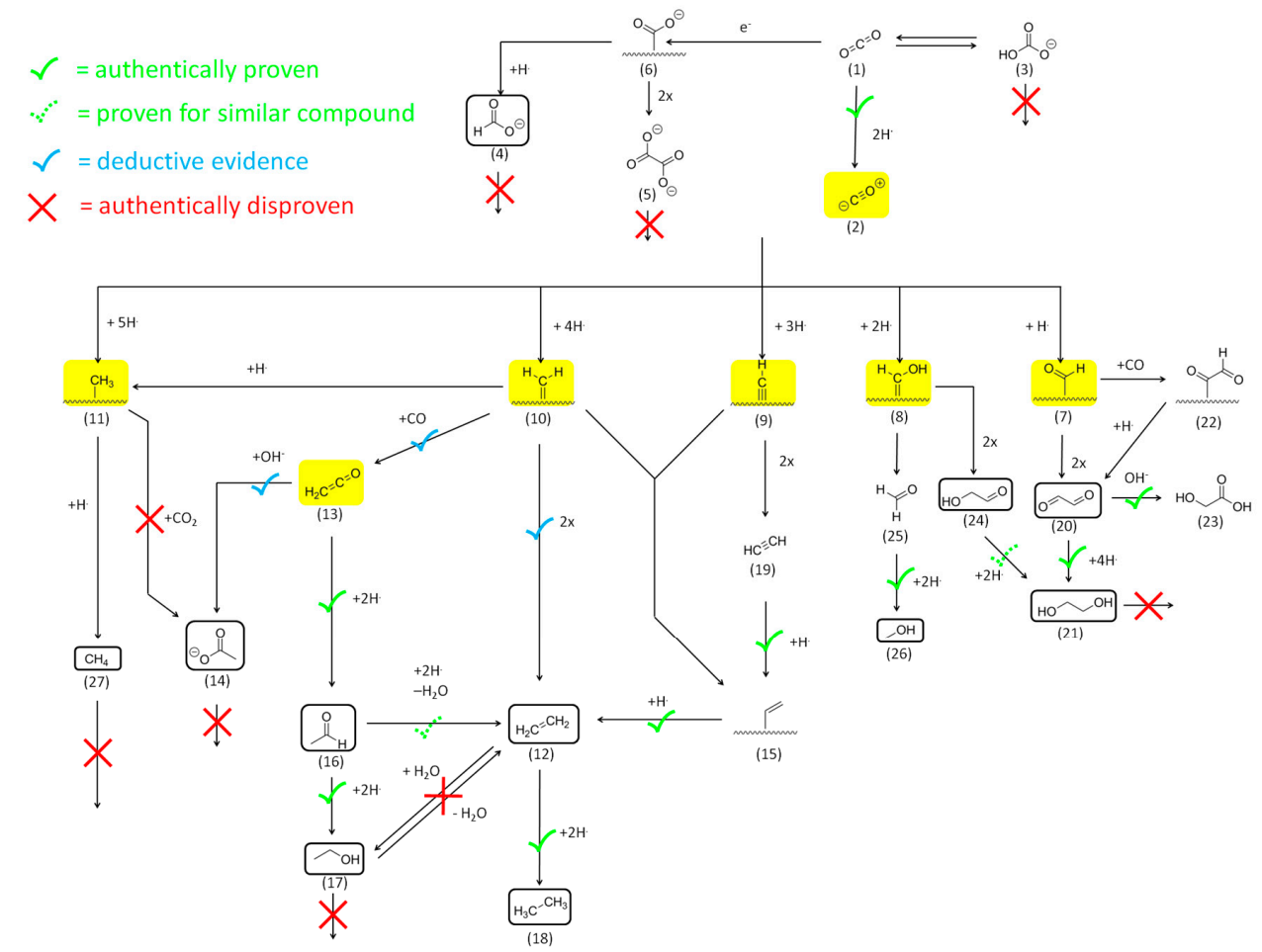

Scheme 1. Proposed mechanism for $\mathrm{CO}_{2}$ electro-reduction on copper-based electrodes. Experimentally disproven pathways are indicated by a red cross. Detectable products are shown with a black frame, key intermediates are highlighted.

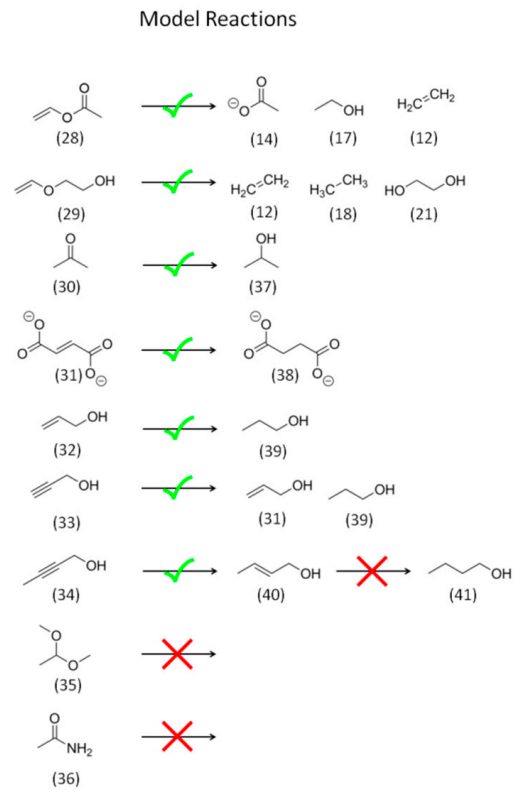

Scheme 2. Model reaction supporting the pathways as depicted in Scheme 1. 


\subsubsection{Reactivity of $\mathrm{CO}_{2}$ and $\mathrm{HCO}_{3}{ }^{-}$}

In order to exclude any perturbation, it was verified that $\mathrm{HCO}_{3}{ }^{-}$is inert under these conditions. Electrolysis in an Ar-purged $\mathrm{KHCO}_{3}$ electrolyte indeed yielded only $\mathrm{H}_{2}$. Importantly, $\mathrm{KOH}$ was used as anolyte to ensure that no gaseous $\mathrm{CO}_{2}$ is liberated at the cation exchange membrane.

\subsubsection{Reactivity and Role of $2 \mathrm{e}^{-}$Carboxylate Species}

As the screening is related to $\mathrm{CO}_{2}$ electrolysis, reagents were chosen that derive from $\mathrm{CO}_{2}$ by 2 electron $\left(\mathrm{e}^{-}\right)$reduction. $\mathrm{CO}(2)$ is the key intermediate toward all higher reduced products. $[20,32,34,35,58]$. This could also be verified for the model catalyst. Conclusively, the first key step in our scheme is the reduction of physically dissolved or gaseous $\mathrm{CO}_{2}$ (1) to $\mathrm{CO}(2)$.

In $\mathrm{CO}_{2}$ electrolysis, formate (4) and oxalate (5) as well as their conjugated alcohols methanol (26) and ethylene glycol (21) are found. Addition of formate (4) to the electrolyte under argon purging, however, did not yield any reduction products. Its reduction to methanol is evidently possible as ligand on a heavy metal complex [59], but not on copper cathode with competing HER. Like $\mathrm{HCO}_{3}{ }^{-}$ (3) and $\mathrm{CO}_{2}$, also formate (4) is related to $\mathrm{CO}(2)$ as its hydrate form. In both cases, only the neutral gaseous form was found to be electrochemically active.

Despite it never having been observed in our system, oxalate (5) was also used as reactant. Firstly, it is well known in anhydrous electrolytes, where carboxyl-radicals (6) usually dimerise (6) $\rightarrow$ (5) instead of being reduced by a hydrogen radical (6) $\rightarrow$ (4). Secondly, it is a C2 building block and, therefore, a possible intermediate to ethanol (17) or ethylene glycol (21). Yet, no evidence for electrochemical conversion of oxalate (5) could be found even after passing more than $4 \mathrm{e}^{-}$per molecule into the system. Thus, oxalate is a dead end.

\subsubsection{Reactivity of Higher Carboxylates}

Ethanol (17) could arguably also from by reduction of acetate (14). However, when adding sodium acetate to our model system, no evidence was found for acetate (14) being further reduced to any liquid or gaseous product. This result, together with the results from formate (4) and oxalate (5), suggests that carboxylates in general are inert to electro-reduction by the in situ-grown copper catalyst. Acetamide (36), which in contrast to acetate is not negatively charged, also underwent no transformation. Also carboxylate groups, which are part of an $\alpha, \beta$-unsaturated $\pi$-system as in fumarate (31), remain untouched.

\subsubsection{The Role of Acetaldehyde Acyl-Species and Enolates}

In the literature, several pathways to hydrocarbon products are discussed. The most widely accepted one begins by formation of a $\mathrm{C}_{2} \mathrm{O}_{2}$ intermediate and is supported by the work of the Hori [60] and the Koper group [44]. Ma et al., recently proposed a mechanism under high current density conditions, featuring ketene (13) and methylene (10) as key intermediates [57]. In this mechanism, ethene (12) is produced by dimerisation of two methylene (10) units. Ethanol (17) is formed by carbonylation of one methylene (10) to ketene (13) and two subsequent reduction steps to acetaldehyde (16) and ethanol (17). Both these mechanisms feature acetalydehyde (16) as an intermediate. In the first mechanism, it is the "Selectivity Determining Intermediate" (SDI) and precursor to ethene (12) and ethanol (17) [44-46]. In the latter, it is only precursor to ethanol (17).

Bertheussen et al. [52] recently reported the observation of considerable quantities of acetaldehyde (16) in an authentic electrolysis experiment and demonstrated the authentic bulk electro-hydrogenation of acetaldehyde (16). We attempted to reproduce these results and also intended to demonstrate the ethene (12) from acetaldehyde (16). The affinity of the catalyst towards aldehydes is very high, even under elevated current density conditions. Addition of acetaldehyde (16) to a running electrolysis under Ar purging suppressed the HER from $100 \%$ to $4 \%$. This affinity was also reflected in the WE 
potential, which rose from $-1.86 \mathrm{~V}$ to $-1.39 \mathrm{~V}$ vs. $\mathrm{Ag} / \mathrm{AgCl}$ by addition of the acetaldehyde (16) at a current density of $30 \mathrm{mAcm}^{-2}$.

While we could also confirm the reduction of acetaldehyde (16) to ethanol (17) under our model conditions, no ethene (12) could be found in the gas phase. This contradicts an ethene formation from acetaldehyde (16) and rather supports the scheme of Ma et al., where only ethanol (17) is formed from acetaldehyde (16) [57].

DFT calculation for the $\mathrm{C}_{2} \mathrm{O}_{2}$ mechanism suggests that acetaldehyde (16) is adsorbed in its enolate form [44-46]. To enforce this tautomeric form, vinyl acetate (28) and ethylene glycol vinyl ether (29) were used as models for enolates.

Indeed, in both cases ethene (12) evolution was observed. Vinyl acetate (28) reduction however suffered from the participation of free acetaldehyde (16) from saponification of the ester. The bulk of the reagent was actually converted into ethanol (17) and acetate (14). The appearance of small quantities of $n$-butanol (41) proved the presence of free acetaldehyde (16). In contrast to the ester, the ether protection group was stable against hydrolysis. Indeed, its addition yielded only ethylene glycol (21) in the liquid phase and ethene (12) and ethane (18) in the gas phase. This can only be explained by an oxidative addition/dissociative adsorption of the vinyl-ether (29) into an alcoholate and a copper vinyl complex (15), which was then terminated by a hydrogen-radical or reduced. This, on the other hand, supports an ethene (12) formation from acetaldehyde (16) as featured in the $\mathrm{C}_{2} \mathrm{O}_{2}$-based mechanism.

An explanation for these ambiguous results may be different potential and current density regimes. The $\mathrm{C}_{2} \mathrm{O}_{2}$ mechanism was derived a specific crystal plane $\mathrm{Cu}(100)$ and a potential of $-0.4 \mathrm{~V}--0.45 \mathrm{~V}[45,46]$ vs. RHE.

In the case of this study, a dendritic catalyst was used at around $-1.0 \mathrm{~V}$ vs. RHE. Under such conditions, other mechanistic pathways on other crystal planes may prevail. This is supported by recent results provided by Surendranath [61] and coworkers, who found a $\mathrm{pH}$-invariant strong rise of the CO-binding ability of copper surface for potentials more negative than $-0.6 \mathrm{~V}$ and a saturation of CO-binding strength for potentials more negative than $-0.8 \mathrm{~V}$. This clearly sets up two different potential regimes. This study and the work of Ma et al. [57] were both executed in a high current density and, therefore, high overpotentials regime. It appears that under high overpotentials, the rate of electro-hydrogenation of acetaldehyde (16) vastly exceeds the rate of $\mathrm{sp}^{2} \mathrm{C}-\mathrm{O}$ bond cleavage. However, the reaction can be enforced using protection groups. This again emphasizes that the mechanisms at onset potentials and high current densities are not necessarily comparable.

There appear to be multiple pathways to ethene (12), which become accessible under different potentials. Recently, Ledezma-Yanez et al., also reported that the hydrogenation or cleavage of acetaldehyde (16) is very site-sensitive [62], which may play an important role on a dendritic catalyst. Nevertheless, the same catalyst that was used for the acetaldehyde reduction yields higher FEs for ethene (12) than ethanol (17) for $\mathrm{CO}_{2} \mathrm{RR}$. The lack of ethene observation therefore cannot be a sole site effect.

The reductive cleavage of vinyl alcohol derivatives is actually a very interesting reaction even if just considered an electrochemical bulk transformation on its own. It is an electrochemical Reverse Wacker Oxidation.

\subsubsection{Reactivity of $\mathrm{C}=\mathrm{O}$ Double Bonds}

The mechanistic scheme that is presented here features many electro-hydrogenations of $\mathrm{C}=\mathrm{O}$ and $\mathrm{C}=\mathrm{C}$ bonds, which were therefore studied in detail. Aldehydes, as mentioned above, readily undergo electro-hydrogenation to the corresponding alcohols. To further probe the reactivity of $\mathrm{C}=\mathrm{O}$ double bonds, also acetone (30) was evaluated and $i$-propanol (37) was obtained. Reactivity-wise, however, already this simplest ketone acetone (30) was far less reactive than the aldehydes. The WE potential did not change notably when it was added. Less than $10 \%$ were actually converted after passing $4.8 \mathrm{~F} / \mathrm{mol}$. It cannot be ruled out that, in case of ketones, the reduction takes place via hydrogen in statu nascendi. There are no reliable reports about $i$-propanol (37) or any other secondary alcohols in 
$\mathrm{CO}_{2} \mathrm{RR}$. In this case, this is due to the low reactivity of the corresponding ketones and, therefore, the lack of an efficient formation pathway.

As origin of acetaldehyde Bertheussen et al. [52] proposed a surface $\mathrm{HC}_{2} \mathrm{O}_{2}$ intermediate (22) towards the formation of acetaldehyde (16). Its mono-hydrogenation may yield glyoxal (20), which was also found by Kuhl et al. [17]. Subsequent hydrogenation of glyoxal (20) yielded ethylene glycol (21). In conclusion, glyoxal (20) is an intermediate to ethylene glycol (21), which is also found in $\mathrm{Cu}$-catalyzed $\mathrm{CO}_{2}$ reduction, usually at low overpotentials. It should be noted that glyoxal (20) also rapidly undergoes benzilic-acid rearrangement [63] when exposed to high $\mathrm{pH}$ values as present in the vicinity of the electrode to yield glycolic acid (23) [64].

In the $\mathrm{C}_{2} \mathrm{O}_{2}$-based low overpotential mechanism, the reduction to acetaldehyde (16) also proceeds via $\mathrm{sp}^{2} \mathrm{C}-\mathrm{O}$ bond cleavages. As for acetaldehyde (16), also in this case the balance between $\mathrm{C}-\mathrm{O}$ bond cleavage and $\mathrm{C}=\mathrm{O}$ bond hydrogenation may shift completely to the latter at higher overpotentials. Ethylene glycol (21) evolves at lower overpotentials ( $>-0.9 \mathrm{~V}$ vs. RHE) [17] than those where pronounced ethene (12), ethanol (17) or acetate (14) evolution is observed ( $<-1.1 \mathrm{~V}$ vs. RHE). Thus, $\mathrm{C}_{2} \mathrm{O}_{2}$ and $\mathrm{HC}_{2} \mathrm{O}_{2}$ species (22) are evidently present at very low overpotentials, as suggested by the Strasser, Chorkendorff and Nørskov groups [16,51,52,65] and may yield acetaldehyde (16) as intermediate for ethanol (17) and ethene (12) evolution at low overpotentials, which yet is no longer valid at high current densities. These conditions, however, are not within the scope of this work.

$\mathrm{CO}(2)$ and $\mathrm{HCO}(7)$ species, which are proposed to form $\mathrm{C}_{2} \mathrm{O}_{2}$ or $\mathrm{HC}_{2} \mathrm{O}_{2}$ (22), are also precursors for methanol (26) via formaldehyde (25) as intermediate. Formaldehyde (25) in the experiment was rapidly reduced and fully converted to methanol (26). Noteworthy, no other products were observed. Formaldehyde (25) was controversially discussed as intermediate for chain growth in Fischer-Tropsch chemistry [66]. Also for $\mathrm{CO}_{2} \mathrm{RR}$ no evidence for $\mathrm{C}-\mathrm{C}$ bond formation from formaldehyde (25) was found. In conclusion, the liberation of formaldehyde (25) from surface formyl (7) or hydroxycarbene (8) species is irreversible.

\subsubsection{Reactivity of Alcohols and Ethers}

Ethylene glycol (21) was also proposed as an intermediate to ethanol (17) [17]. The cleavage of ethylene glycol vinyl ether (28) has proven that $\mathrm{C}-\mathrm{O}$ bond cleavage is possible also for non-organometallic intermediates. Addition of ethylene glycol (21) to our model electrolysis did not yield any reduction products nor affected potential or HER. Likewise, ethanol (17) did not undergo any transformations, for example, to ethane (18). In contrast to the aforementioned enol-ether (29), acetaldehyde-dimethylacetal (35) (Scheme 2) also did not react. It was concluded that, in general, saturated compounds and alcohols are inert towards reduction by an in situ-grown copper electro-catalyst. The $\mathrm{C}-\mathrm{O}$ single bond cleavage appears to be limited to strongly adsorbed high energy species with multiple bonds to the surface as CO (2), hydroxymethylene (8), hydroxymethyne [17], and $\mathrm{CO}_{2} \bullet-(6)$, which cannot exist as free molecules in solution or enolates under specific conditions.

The strong driving force for the reduction of such species as opposed to their liberation is reflected in the almost negligible FEs for methanol $(\mathbf{2 6})(<0.1 \%)$ as opposed to $\mathrm{C} 2$ or C3 products with only one oxygen-containing functional group (e.g., ethanol (17), acetate (14) and $n$-propanol (39)) in this system. We have experimentally proven that neither formaldehyde (25) nor formate (4), once liberated, can be re-adsorbed and reduced to the $\mathrm{C} 1$ carbene precursors for ethanol, acetate or ethene (12).

\subsubsection{Reactivity of Alkenes}

The first experiments concerning $\mathrm{C}=\mathrm{C}$ double bonds were carried out with allyl alcohol (32), as both ally alcohol (32) and its saturated pendant $n$-propanol (39) are present in the $\mathrm{CO}_{2} \mathrm{RR}$ product scope. Addition of allyl alcohol (32) to the electrolyte while purging with argon yielded n-propanol (39). Thusly, the formation of $n$-propanol (39) proceeds, at least partially, via the intermediate allyl alcohol (32), which therefore is never observed in large quantities. The complete discussion of the C3-product scope of copper catalyzed $\mathrm{CO}_{2}$ reduction is out of scope for this publication. This experiment 
authentically demonstrated that electro-hydrogenation of $C=C$ double bonds are feasible reaction steps on the surface of a copper electrode. It is actually quite surprising, that a rather electron-rich alkene like allyl alcohol (32), which is therefore deactivated towards reduction, is electro-hydrogenated by the in situ-grown copper catalyst with competing HER.

Some references of copper-catalyzed $\mathrm{CO}_{2} \mathrm{RR}$ mention trace amounts of ethane (18) [20]. Taking the results with allyl alcohol into concert, we concluded that ethane (18) must originate from the in situ electro-hydrogenation of ethene (12). This was verified by using ethene (12) as feed gas, which was partially reduced to ethane (18). The conversion was very low $(0.03 \%$ conversion, $2.2 \% \mathrm{FE})$ and the HER was barely attenuated. This observation is in agreement with literature reports of high ethane (18) efficiencies being rare. The ethene (12) hydrogenation ability of the in situ-grown copper electro-catalysts and, obviously, most other copper-based systems, is rather poor. Examination of the liquid phase did not show any products, which ruled out that ethanol (17) is at least partially produced by in situ hydration of ethene (12) $\rightarrow$ (17).

In contrast to ethene (12) and allyl alcohol (32), electron-poor double bonds are very reactive. This was confirmed by electro-reduction of potassium fumarate (31). Potassium succimate (38) was observed as sole product of this reaction.

The transformation was particularly interesting as the conversion was quantitative and the HER was completely suppressed after addition. This behavior was also reflected in the WE potential, which dropped from $-1.83 \mathrm{~V}$ to $-1.34 \mathrm{~V}$ vs. $\mathrm{Ag} / \mathrm{AgCl}$ upon addition (also see Figures S9 and $\mathrm{S} 10$ in the Supplementary Materials (SM)).

The copper electro-catalyst, in conclusion, has certain ability for alkene hydrogenation yet requires activated substrates. This is in full agreement with the actual $\mathrm{CO}_{2} \mathrm{RR}$ product spectrum, which features several electron-rich alkenes, yet no electron-deficient alkenes, and suggests the latter as highly reactive intermediates.

\subsubsection{Reactivity of Alkynes}

Several even very different mechanistic models incorporate carbyne species $[17,44,45]$. As the dimerization of carbynes to alkynes is even known to proceed on single metal centers [67], they could also be proposed as intermediates. As models for triple-bond ethyne (19), propargyl alcohol (33) and 2-butyn-1-ol (34) were used. The latter served as model for an internal triple bond. C $\equiv \mathrm{C}$ triple bonds turned out to be surprisingly reactive towards the in situ-grown copper catalyst. In our experiment, the transformation of propargyl alcohol (33) to allyl alcohol (32) was quantitative with only small amounts of $n$-propanol (37) found from further reduction. Allyl alcohol (32) as reactant gave much lower conversion of $34 \%$ at more charge per moles passed. Also, the addition of propargyl alcohol (33) completely suppressed the HER and lowered the WE potential to $-1.41 \mathrm{~V}$ at $30 \mathrm{mAcm}^{-2}$, while allyl alcohol was reduced with only $15 \% \mathrm{FE}$ at $-1.67 \mathrm{~V}$.

Reduction of ethyne (19) gave ethene (12) as major product. Small quantities of ethane (18) were also observed. Analysis of the electrolyte showed no further liquid products. The HER could not be totally suppressed probably due to the poor solubility of ethyne (19) in water. However, up to $61 \%$ of the charge passed went into the reduction of ethyne (19) to ethene (12) as opposed to $2 \%$ ethane (18) yield for ethene (12) feed. Palladium, a noble metal well known for its hydrogenation activity, was also recently reported to selectively electro-hydrogenate ethyne (19) to ethene (12) by Song et al. [68]. Finding a similar behavior for copper is a terrific result, not only giving insight to copper-catalyzed $\mathrm{CO}_{2}$ electro-reduction, but also opening new pathways for organic electro-synthesis.

In all experiments, we found a strong preference for the reduction of triple bonds over double bonds. A straightforward explanation for this may be that terminal alkynes form copper alkynides even in the presence of rather weak bases, which leads to a much stronger adsorption than the $\pi$-complexes that are formed by alkenes. In order to clarify the role of alkynides, the internal alkyne 2-butyn-1-ol (34) was used as model reactant. The results contradict the alkynide theory. Despite being more sterically hindered and more electronically deactivated, 2-butyn-1-ol (34) showed much higher reactivity and 
higher conversion than allyl alcohol (32). Noteworthy, while the conversion to crotyl alcohol (40) was quantitative, $n$-butanol (41) was only observed in barely detectable traces, though the charge passed into the system was more than enough $(4.8 \mathrm{~F} / \mathrm{mol}$ passed, 4 needed) to convert the whole sample into $n$-butanol. The resulting crotyl alcohol (40) is already too sterically hindered to be reduced by the copper catalyst in aqueous environment. The effect on the WE potential for 2-butyn-1-ol (34) was not as pronounced as for terminal alkenes and more comparable to allyl alcohol (32). The participation of acetylide species (9) in the case of terminal alkenes therefore cannot be fully ruled out. Yet, it is not the sole explanation for the high reactivity of triple bonds toward Cu-catalyzed electro-reduction.

As for electron-deficient alkenes, also in the case of alkynes, their high reactivity rather renders them highly reactive intermediates than products without formation pathway. Due to these results, we propose the participation of ethyne (19) and vinyl (15) species in the formation of ethene (12). The first can be formed from carbyne-carbyne $(\mathbf{9}, 9)$ coupling on the surface, the latter from carbyne-carbene $(9,10)$ coupling or re-adsorption and one electron reduction of ethyne (19). We found a high reduction activity of in situ-grown copper electro-catalysts toward $C \equiv C$ triple bonds. It appears plausible that ethyne (19) may be formed as intermediate but is quantitatively reduced to ethene (12) and therefore not observed.

It is worth mentioning that carbene (10) and carbyne (9) species are also featured in the $\mathrm{C}_{2} \mathrm{O}_{2}$ mechanism as intermediates towards methane (27) but not ethene (12) [44-46]. At very small conversion rates, the population of methylene units may indeed be too low for a reasonable rate of dimerisation. At elevated current densities and the corresponding high overpotentials and conversion rates, dimerisation becomes more feasible and may prevail over ethene (12) formation from acetaldehyde (16) which in this regime is exclusively reduced to ethanol (17). The same concept also applies to carbyne (9) intermediates, which can either dimerise to the evidently rapidly reduced ethyne (19) or be coupled with methylene (10) to vinyl (15) species that also yield ethene (12).

\subsection{CO Bulk Electrolysis at High Current Density}

From the perspective of $\mathrm{CO}_{2}$ reduction, the most straightforward model reactant is actually $\mathrm{CO}$ (2). Thusly, we chose to directly compare $\mathrm{CO}_{2}(1)$ and $\mathrm{CO}$ (2) under identical high current density conditions (Figure 2). Like in the original publication [54], these experiments were conducted with gas diffusion electrodes at $170 \mathrm{mAcm}^{-2}$.

In analogy to the $\mathrm{CO}_{2}$ benchmark, the gaseous and liquid products were sampled every $10 \mathrm{~min}$. $\mathrm{CO}$ (2) electrolysis yielded a product distribution, that was surprisingly similar to the one observed with $\mathrm{CO}_{2}(\mathbf{1})$ under the same conditions.

Thus, CO (2) is key intermediated to most products, which also corresponds to current literature $[50,52,58,61]$. The most prominent difference was the absence of formate (4) as product. As we have shown, this electro-catalyst is not capable of formate reduction. Thus, formate (4) is exclusively formed from $\mathrm{CO}_{2}(\mathbf{1})$.

As for $\mathrm{CO}_{2}$ reduction, the catalyst also showed a good selectivity for carbon products, but with a different product distribution pattern.

The FE of acetate (14) (yellow in Figure 2) reached 11\% after $40 \mathrm{~min}$, which corresponds to $18.7 \mathrm{mAcm}^{-2}$ specific current density. Compared to the $\mathrm{CO}_{2}$ bulk electrolysis, this is an increase of $300 \%$ in the total amount formed and a factor of two in FE. The effect was less pronounced for ethanol (17). The FE was increased to $29 \%$ (light green in Figure 2) and the specific current density reached $49.8 \mathrm{mAcm}^{-2}$. Nevertheless, this still results in a $90 \%$ increase of ethanol (17) formation rate and is the highest ever reported specific current density for ethanol formation from $\mathrm{CO}$ (2). 


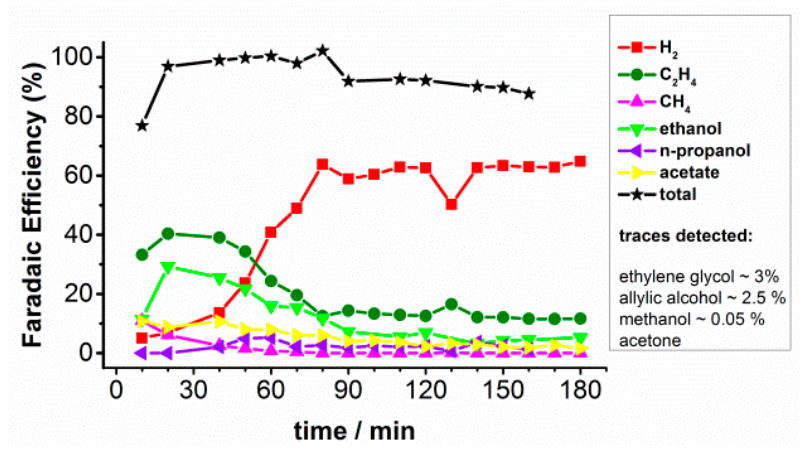

Figure 2. FE vs. time for major products of $\mathrm{CO}$ bulk electrolysis at $170 \mathrm{mAcm}^{-2}$.

\section{Mechanistic Conclusions: Acetate and Ketene}

The massive increase of acetate (14) formation in the case of CO (2) feed may lead to several mechanistic conclusions. It demonstrates that the acetate (14) does not originate from nucleophilic reactions between surface methyl species (11) and $\mathrm{CO}_{2}(\mathbf{1})$ as its formation is even enhanced in absence of $\mathrm{CO}_{2}$ (1). In fact, the formation of acetate is not covered by the $\mathrm{C}_{2} \mathrm{O}_{2}$ mechanism [44-46]. This is different for the scheme suggested by Ma et al., The formation of ketene (13) from $\mathrm{CO}$ (2) and methylene (10) is a well-known reaction in molecular organometallic chemistry of copper, nickel and iron [69-71]. Several publications also show that the dimerisation of methylene (10) and the carbonylation to ketene (13) are competing reactions and the carbonylation can proceed by coupling with endogenous and capture of exogenous $\mathrm{CO}(2)$ [72,73]. Introducing an additional path to Ma's scheme, where ketene is not reduced to acetaldehyde (16) but hydrated, explains the occurrence of acetate (14) in straightforward manner in line with known chemical reactivity.

In the comparison experiment, both putative products of ketene (13), ethanol (17) and acetate (14), were significantly pronounced, while ethene (12) showed the same current yield. This goes well with the model of ketene (13) as "Selectivity Determining Intermediate" (SDI) for ethanol (17) and acetate (14), as its formation is promoted by a higher abundance of CO (2). Ethene (12) formation, on the other hand, is not affected by the $\mathrm{CO}$ (2) concentration. As methylene (10) dimerisation does not involve $\mathrm{CO}$ (2) addition, this points to methylene (10) as "SDI" for ethene (12) and ethanol (17)/acetate (14). Surendranth and coworkers have recently proven that under high current densities, $\mathrm{CO}_{\mathrm{ads}}$ is in a potential-invariant quasi equilibrium with $\mathrm{CO}_{\text {free }}$ [61]. This would also support an enhancement for carbonylation reaction in presence of high $\mathrm{CO}$ concentrations.

\section{Materials and Methods}

Electrolytes were prepared form deionised water (ISO 3686) with a resistance of $18.2 \mathrm{M} \Omega \mathrm{cm}^{-1}$ (Milli-Q Advantage A10 water purification system: Merck, Darmstadt, Germany). KBr and $\mathrm{KOH}$ were purchased from Alpha Aesar (Haverhill, MA, USA) in $>99 \%$ and p.a. purity. $5 \mathrm{~N} \mathrm{CuSO}_{4}$ purchased from Alpha Aesar (Haverhill, MA, USA) and recrystallised once from water prior to use.

$4.5 \mathrm{~N} \mathrm{CO}_{2}, 4.7 \mathrm{~N} \mathrm{CO}, 4.5 \mathrm{~N}$ ethylene, $4.5 \mathrm{~N}$ methane and solvent free ethyne were purchased from Linde AG (Munich, Germany). The examined model compounds were purchased from ABCR (Karlsruhe, Germany) and Sigma Aldrich (St. Louis, MO, USA) in p.a. or better quality and used without further purification. $5 \mathrm{~N} \mathrm{H}_{2} \mathrm{SO}_{4}$ was purchased from Alpha Aesar (Haverhill, MA, USA) and used as received.

Deuterated solvents and internal NMR standards were purchased form Sigma Aldrich (St. Louis, MO, USA).

Carbon GDL's were purchased from FuelCellsEtc (College Station, TX, USA). Electrochemical measurements were conducted on a Metrohm Autolab PGSTAT302N potentiostate-galvanostate (Deutsche Methrom GmbH \& Co KG, Filderstadt, Germany). 
Gas composition was analyzed on a Thermo Scientific Trace 1310 gas chromatograph (Thermo Fisher Scientific, Waltham, MA, USA) (custom setup purchased from S+H Analytik, Mönchengladbach, Germany). Carbon monoxide, ethylene, ethane, methane and carbon dioxide were separated on a Shincarbon ${ }^{\mathrm{TM}}$ column (Restek, Bellefonte, PA, USA) using He as carrier coupled to a thermal conductivity detector (TCD). Hydrogen was analyzed on a $5 \AA$ molecular sieves column (Restek, Bellefonte, PA, USA) with Ar carrier also coupled to a TCD.

NMR Spectra were recorded on a Bruker Avance 400 (400 MHz) NMR spectrometer (Bruker, Billerica, MA, USA) equipped with a Autotune BBO, $5 \mathrm{~mm},{ }^{109} \mathrm{Ag}^{-31} \mathrm{P}$ probehead and pulsed field gradient unit. NMR spectra were recorded using the "composite pulses"—presaturation pulse sequence for water suppression. For each spectrum 32 scans were accumulated. The D1-delay was set to $4 \mathrm{~s}$ to ensure total spin relaxation after each pulse. NMR-samples were prepared according to the following protocol. To $300 \mu \mathrm{L}$ of electrolyte $250 \mu \mathrm{L}$ of $D_{2} \mathrm{O}$ and $50 \mu \mathrm{L}$ of an internal standard stock solution was added. A $1.2 \mathrm{M}$ aqueous solution of dimethylsulfone $\left(\mathrm{DMSO}_{2}\right)$ was used as internal standard. For experiments with $\mathrm{CO}$ feed a $0.06 \mathrm{M}$ solution of potassium fumarate was used as we found that $\mathrm{DMSO}_{2}$ is prone to undergo $\mathrm{H} / \mathrm{D}$-exchange with the solvent under elevated $\mathrm{pH}$-values as present in our $\mathrm{CO}$-feed experiments.

Experiments with $\mathrm{CO}_{2}, \mathrm{CO}$, potassium formate and sodium acetate were conducted in a stacked flow cell purchased from ElectroCell (Tarm, Denmark) (see Figure S1 (SM) for exact configuration). Anolyte and catholyte are pumped through the cell in 2 separate cycles by a peristaltic pump (Ismatec, Wertheim, Germany) at $100 \mathrm{~mL} / \mathrm{min}$. Hydrophobic carbon based commercial gas diffusion layers of the types Freudenberg H2315 C2 ${ }^{\mathrm{TM}}$ and Sigracet $25 \mathrm{BC}^{\mathrm{TM}}$ were used as working electrode blanks. The GDLs show comparable results. Figures 1 and 2 show result received on the Freundenberg GDL. The GDL was mounted in a Capton ${ }^{\circledR}$-sealed Cu-ETP frame with an electrochemically active area of $3.3 \mathrm{~cm}^{2} . \mathrm{CO}_{2} / \mathrm{CO}$ was supplied from behind and flowed through the GDL and the in situ grown copper layer into the electrolyte. The gases were fed with $50 \mathrm{sccm}$ against atmospheric pressure using Bronkhorst (Ruurlo, The Netherlands) el-flow ${ }^{\mathrm{TM}}$ mass flow controllers. An $\mathrm{Ag} / \mathrm{AgCl} / 3 \mathrm{M} \mathrm{KCl}$

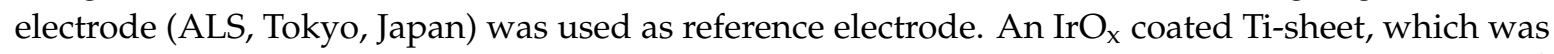
purchased from ElectroCell (Tarm, Denmark) served as counter electrode with an active area of $10 \mathrm{~cm}^{2}$ active area. The electrolyte compartments were separated by a Nafion N 117 (DuPont, Wilmington, $\mathrm{DE}, \mathrm{USA}$ ) membrane to prevent crossover of products and reagents. The $\mathrm{pH}$-value in the electrolyte reservoir was recorded using a Methrom Unitrode ${ }^{\mathrm{TM}}$ (Deutsche Methrom GmbH Co KG, Filderstadt, Germany) coupled to a pX-1000 module ${ }^{\mathrm{TM}}$ in the workstation. The overall voltage was monitored on a second pX-1000 module ${ }^{\mathrm{TM}}$ (Deutsche Methrom GmbH \& Co KG, Filderstadt, Germany).

An aqueous solution of $0.1 \mathrm{M} \mathrm{KBr}$ was used as cathoyte and $2.5 \mathrm{M} \mathrm{KOH}$ as anolyte. $6.5 \mathrm{mM} \mathrm{CuSO}_{4}$ was added to the catholyte as copper source for in situ catalyst preparation. The initial $\mathrm{pH}$-value of the electrolyte was adjusted to 2 by addition of $0.005 \mathrm{M}$ sulfuric acid.

Bulk electrolysis was conducted in galvanostatic mode at $170 \mathrm{mAcm}^{-2}$ for $3 \mathrm{~h}$. During this time the gas stream was sampled in gas tight bags over $10 \mathrm{~min}$ intervals. In parallel $1 \mathrm{~mL}$ aliquots of the catholyte were sampled every $10 \mathrm{~min}$.

Reactivity experiments were conducted in an H-type glass cell (custom cell, manufactured by Normag Labor- und Prozesstechnik GmbH, Ilmenau, Germany) with $5 \mathrm{~mL}$ electrolyte volume (per electrode), a $1 \mathrm{~cm}^{2}$ polished $\mathrm{Cu}$ sheet working electrode, $\mathrm{Ag} / \mathrm{AgCl} 3 \mathrm{M} \mathrm{KCl}$ reference electrode (ALS, Tokyo, Japan) and Pt-wire counter electrode. Nafion N117 was used as separator. Electrolytes had the same composition as in the flow cell setup. The reactivity essay was conducted after the following procedure. The catalyst was grown over a period of $10 \mathrm{~min}$ at a total current of $30 \mathrm{~mA}$ and continuous $10 \mathrm{sccm}$ Ar purging. After this period the model reactant was added. Gases were supplied with $10 \mathrm{sccm}$. Solids were weighed to $0.5 \mathrm{mM}$ and added dissolved in a small amount of electrolyte. Liquids were added neat in and 32 or $50 \mu \mathrm{L}$ aliquot. Solid acids were neutralized with an equimolar amount of $5 \mathrm{M} \mathrm{KOH}$ prior to addition. 


\section{Conclusions}

The cathodic reactivity of the previously presented in situ-grown copper catalyst towards various small molecules and functional groups was studied in detail. The spectrum of gaseous and liquid products of every transformation was fully characterized.

Several transformations, which were suggested by literature or DFT predictions such as the formation from ally alcohol to $n$-propanol, acetaldehyde to ethanol, ethane to ethane or glyoxal to ethylene glycol, were demonstrated.

The reductive cleavage of enols, which is a central reaction in the low overpotential evolution of ethene from acetaldehyde as intermediate, could be experimentally verified by the cleavage of two vinyl alcohol derivatives. However, the high current density formation of ethene from free acetaldehyde itself was not possible on the investigated catalyst. Reduction to ethanol is highly preferred in this system. Therefore, its high yield of ethene in $\mathrm{CO}_{2}$ and $\mathrm{CO}$ reduction must be formed on another pathway. An ethene formation by methylene dimerisation as suggested by Ma et al., was found feasible and the scheme could be even extended for further products, such as acetate, methanol or ethylene glycol.

The reduction of carboxylates was excluded for five model reagents.

The appearance of alkene products such as ethene and allyl alcohol was found to originate from a poor electro-hydrogenation capability of the copper catalyst.

The absence of secondary alcohols, aldehydes, electron-deficient alkenes and alkynes was elucidated with different results. Secondary alcohols cannot be formed due to the low ketone reduction activity of the catalyst. Aldehydes, electron-deficient alkenes and alkynes, on the other hand, are surprisingly efficiently hydrogenated by the in situ-grown copper catalyst yielding functional groups present in the $\mathrm{CO}_{2} \mathrm{RR}$ product scope. Putative intermediates such as ethyne, ketene or acrolein therefore cannot be observed in the electrolyte or with high surface concentrations, especially at the high overpotentials at which they are proposed. Further studies are required to clarify their presence.

Supplementary Materials: The following are available online at www.mdpi.com/2073-4344/7/5/161/s1, NMR spectra, relevant GC data, additional electric characteristics, economical estimation for ethene.

Acknowledgments: We gratefully thank Walter Bauer, Harald Maid and Christian Placht for access and support to the NMR spectrometers.

Author Contributions: B.S. and G.S. conceived and designed the experiments; B.S. performed the experiments; C.R. developed the catalyst and its deposition parameters. B.S., C.R. and G.S. analyzed the data; S.S.N. contributed to the interpretation of the results by discussion and related work; B.S. and in minor part G.S. wrote the paper; M.F. is the industrial sponsor of B.S. and contributed with valuable discussions; R.D. is the academic supervisor of B.S.; G.S. is the industrial supervisor and developed the $\mathrm{CO}_{2}$-reduction program with focus on industrial relevant parameter.

Conflicts of Interest: The authors declare no conflict of interest.

\section{References}

1. DENA Grid Study II. Available online: http://www.dena.de/fileadmin/user_upload/Projekte/ Erneuerbare/Dokumente/dena_Grid_Study_II_-_final_report.pdf (accessed on 17 March 2016).

2. DENA Verteilernetzstudie. Available online: http://www.dena.de/fileadmin/user_upload/Projekte/ Energiesysteme/Dokumente/denaVNS_Abschlussbericht.pdf (accessed on 17 March 2016).

3. Sridhar, N.; Agarwal, A.; Rode, E. Electrochemical Production of Chemicals-Applicability of $\mathrm{CO}_{2}$ Conversion; Det Norse Veritas AS: Oslo, Norway, 2012.

4. Schlögl, R. The Role of Chemistry in the Energy Challenge. ChemSusChem 2010, 3, 209-222. [CrossRef] [PubMed]

5. Qiao, J.; Liu, Y.; Hong, F.; Zang, J. A review of catalysts for the electroreduction of carbon dioxide to produce low-carbon fuels. Chem. Soc. Rev. 2014, 43, 631-675. [CrossRef] [PubMed]

6. Hori, Y. Modern Aspects of Electrochemistry; Vayenas, C.G., White, R.E., Eds.; Springer: New York, NY, USA, 2008; p. 16. ISSN: 0076-9924. 
7. Hori, Y. Handbook of Fuel Cells-Fundamentals, Technology and Applications; Vielstich, W., Lamm, A., Gasteiger, H.A., Eds.; Wiley VCH: Weinheim, Germany, 2003; ISBN 047-1-49-9269.

8. Paik, W.; Andersen, T.N.; Eyring, H. Kinetic studies of the electrolytic reduction of carbon dioxide on the mercury electrode. Electrochim. Acta 1969, 14, 1217-1232. [CrossRef]

9. Hori, Y.; Suzuki, S. Electrolytic Reduction of Carbon Dioxide at Mercury Electrode in Aqueous Solution. Bull. Chem. Soc. Jpn. 1982, 55, 660-665. [CrossRef]

10. Hori, Y.; Kikuchi, K.; Shin Suzuki, K. Production of $\mathrm{CO}$ and $\mathrm{CH}_{4}$ in electrochemical reduction of $\mathrm{CO}_{2}$ at Metal Electrodes in aqueous hydrogencarbonate solution. Chem. Lett. 1985, 14, 1695-1698. [CrossRef]

11. Cook, R.L.; MacDuff, R.C.; Sammels, A.F. On the Electrochemical Reduction of Carbon Dioxide at In Situ electrodeposited Copper. J. Electrochem. Soc. 1988, 135, 1320-1326. [CrossRef]

12. Cook, R.L.; MacDuff, R.C.; Sammels, A.F. High Rate Gas Phase $\mathrm{CO}_{2}$ Reduction to Ethylene and Methane using Gas Diffusion Electrodes. J. Electrochem. Soc. 1990, 137, 607-608. [CrossRef]

13. Hori, Y.; Murata, A.; Takahashi, R. Formation of hydrocarbons in the electrochemical reduction of carbon dioxide at copper electrodes in aqueous solution. J. Chem. Soc. Faraday Trans. 1989, 85, 2309-2326. [CrossRef]

14. Jermann, B.; Augustynski, J. Long-term activation of the copper cathode in the course of $\mathrm{CO}_{2}$ reduction. Electrochim. Acta 1994, 39, 1891-1896. [CrossRef]

15. Ogura, K.; Yano, H.; Shirai, F. Catalytic Reduction of $\mathrm{CO}_{2}$ to Ethylene by Electrolysis at a Three-Phase Interface. J. Electrochem. Soc. 2003, 150, D163-D168. [CrossRef]

16. Verela, A.S.; Kroschel, M.; Reier, P.; Strasser, P. Controlling the selectivity of $\mathrm{CO}_{2}$ electroreduction on copper: The effect of the electrolyte concentration and the importance of the local pH. Catal. Today 2016, 260, 8-13. [CrossRef]

17. Kuhl, K.P.; Cave, E.R.; Abram, D.N.; Jaramillo, T.F. New insights into the electrochemical reduction of carbon dioxide on metallic copper surfaces. Energy Environ. Sci. 2012, 5, 7050-7059. [CrossRef]

18. Li, C.W.; Kanan, M.W. $\mathrm{CO}_{2}$ Reduction at Low Overpotential on $\mathrm{Cu}$ Electrodes Resulting from the reduction of Thick $\mathrm{Cu}_{2} \mathrm{O}$ Films. J. Am. Chem. Soc. 2012, 134, 7231-7234. [CrossRef] [PubMed]

19. Chi, D.; Yang, H.; Du, Y.; Lu, T.; Sui, G.; Wang, H.; Lu, J. Morphology-controlled CuO nanoparticles for the electroreduction of $\mathrm{CO}_{2}$ to ethanol. RCS Adv. 2014, 4, 37329-37332.

20. Kas, R.; Kortlever, R.; Milbrat, A.; Koper, M.T.M.; Maul, G.; Baltrisaitis, J. Electrochemical $\mathrm{CO}_{2}$ reduction on $\mathrm{Cu}_{2} \mathrm{O}$-derived copper nanoparticles: Controlling the selectivity of hydrocarbons. Phys. Chem. Chem. Phys. 2014, 16, 12194-12201. [CrossRef] [PubMed]

21. Mistry, H.; Varela, A.S.; Bonifacio, C.S.; Zegkinoglou, I.; Sinev, I.; Choi, Y.-W.; Kisslinger, K.; Stach, E.A.; Yang, J.C.; Strasser, P.; et al. Highly selective plasma-activated copper catalysts for carbon dioxide reduction to ethylene. Nat. Commun. 2016, 7, 12123. [CrossRef] [PubMed]

22. Schwartz, M.; Cook, R.L.; Kehoe, V.M.; MacDuff, R.C.; Patel, J.; Sammells, A.F. Carbon Dioxide Reduction to Alcohols using Perovskite-Type Electrocatalysts. J. Electrochem. Soc. 1993, 140, 614-618. [CrossRef]

23. Jermann, B. Réduction Electrochimique de Longue Durée du Dioxyde de Carbone sur des Cathodes en Cuivre; Université de Genéve: Geneva, Switzerland, 1995.

24. Chen, C.S.; Handoko, A.D.; Wan, J.H.; Ma, L.; Ren, D.; Yeo, B.S. Stable and selective electrochemical reduction of carbon dioxide to ethylene on copper mesocrystals. Catal. Sci. Technol. 2015, 5, 161-168. [CrossRef]

25. Yano, H.; Tanaka, T.; Nakayama, M.; Ogura, K. Selective electrochemical reduction of $\mathrm{CO}_{2}$ to ethylene at a three-phase interface on copper(I) halide-confined $\mathrm{Cu}$-mesh electrodes in acidic solutions of potassium halides. J. Electroanal Chem. 2004, 565, 287-293. [CrossRef]

26. Ogura, K.; Oohara, R.; Kudo, Y. Reduction of $\mathrm{CO}_{2}$ to Ethylene at Three-Phase Interface Effects of Electrode Substrate and Catalytic Coating. J. Electrochem. Soc. 2005, 152, D213-D219. [CrossRef]

27. Albo, J.; Sáez, A.; Solla-Gullón, J.; Montiel, V.; Irabien, A. Production of methanol from $\mathrm{CO}_{2}$ electroreduction at $\mathrm{Cu}_{2} \mathrm{O}$ and $\mathrm{Cu}_{2} \mathrm{O} / \mathrm{ZnO}$-based electrodes in aqueous solution. Appl. Catal. Environ. 2015, 176, 709-717. [CrossRef]

28. Grote, J.-P.; Zeradjanin, A.R.; Cherevko, S.; Savan, A.; Breitbach, B.; Ludwig, A.; Mayrhofer, K.J.J. Screening of material libraries of electrochemical $\mathrm{CO} 2$ reduction catalysts-Improving the selectivity of $\mathrm{Cu}$ by mixing with Co. J. Catal. 2016, 343, 248-256. [CrossRef]

29. Albo, J.; Vallejo, D.; Beobide, G.; Catillo, O.; Irabien, A. Copper-Based Metal-Organic Porous Materials for $\mathrm{CO}_{2}$ Electrocatalytic Reduction to Alcohols. ChemSusChem 2017, 6, 1100-1109. [CrossRef] [PubMed] 
30. Huan, T.N.; Andreiadis, E.S.; Heidkamp, J.; Simon, P.M.; Derat, E.; Cobo, S.; Royal, G.; Bergmann, A.; Strasser, P.; Dau, H.; et al. From molecular copper complexes to composite electrocatalytic materials for selective reduction of $\mathrm{CO}_{2}$ to formic acid. J. Mater. Chem. A 2015, 3, 3901-3907. [CrossRef]

31. Gatrell, M.; Gupta, N.; Co, A. A review of the aqueous electrochemical reduction of $\mathrm{CO}_{2}$ to hydrocarbons on copper. J. Electroanal. Chem. 2006, 594, 1-19. [CrossRef]

32. Jitaru, M. Electrochemical Carbon Dioxide Reduction-Fundamental and Applied Topics. J. Univ. Chem. Technol. Metall. 2007, 42, 333-344.

33. Oloman, C.; Lui, H. Electrochemical Processing of Carbon Dioxide. ChemSusChem 2008, 1, 385-391. [CrossRef] [PubMed]

34. Mikkelsen, M.; Jørgensen, M.; Krebs, F.C. The teraton challenge. A review of fixation and transformation of carbon dioxide. Energy Environ. Sci. 2010, 3, 43-81. [CrossRef]

35. Whipple, D.T.; Kenis, P.J.A. Prospects of $\mathrm{CO}_{2}$ Utilization via Direct Heterogeneous Electrochemical Reduction. J. Phys. Chem. Lett. 2010, 1, 3451-3458. [CrossRef]

36. Neubauer, S.S.; Krause, R.K.; Schmid, B.; Guldi, D.M.; Schmid, G. Overpotentials and Faraday Efficiencies in $\mathrm{CO}_{2}$ Electrocatalysis-The Impact of 1-Ethyl-3-Methylimidazolium Trifluormethanesulfonate. Adv. Energy Mater. 2016, 6, 1502231. [CrossRef]

37. Seshadri, G.; Lin, C.; Bocarsly, A.B. A new homogeneous electrocatalyst for the reduction of carbon dioxide. J. Electroanal. Chem. 1994, 372, 145-150. [CrossRef]

38. Albo, J.; Beobide, G.; Castano, P.; Irabien, A. Methanol Synthesis from $\mathrm{CO}_{2}$ at $\mathrm{Cu} \mathrm{U}_{2} \mathrm{O} / \mathrm{ZnO}$ promoted by pyridine-based aqueous solutions. J. CO2 Util. 2017, 18, 164-172. [CrossRef]

39. Torelli, D.A.; Francis, S.A.; Crompton, J.C.; Javiert, A.; Thompson, J.R.; Brunschwig, B.S.; Soriaga, M.P.; Lewis, N.S. Nickel-Gallium-Catalyzed Electrochemical Reduction of $\mathrm{CO}_{2}$ to Highly Reduced Products at Low Overpotentials. ACS Catal. 2016, 6, 2100-2104. [CrossRef]

40. Shen, J.; Kortlever, R.; Kas, R.; Birdja, Y.Y.; Diaz-Morales, O.; Kwon, Y.; Ledezma-Yanez, I.; Schouten, K.J.P.; Mul, G.; Koper, M.T.M. Electrocatalytic reduction of carbon dioxide to carbon monoxide and methane at an immobilized cobalt protoprophyrin. Nat. Commun. 2016, 6, 8177. [CrossRef] [PubMed]

41. Peterson, A.A.; Abild-Pedersen, F.; Studt, F.; Rossmeisl, J.; Nørskov, J.K. How copper catalyzes the electroreduction of carbon dioxide into hydrocarbon fuels. Energy Environ. Sci. 2010, 3, 1311-1315. [CrossRef]

42. Nørskov, J.K.; Abild-Pedersen, F.; Studt, F.; Bligaard, T. Density functional theory in surface chemistry and catalysis. Proc. Natl. Acad. Sci. USA 2011, 108, 937-943. [CrossRef] [PubMed]

43. Durand, W.J.; Peterson, A.A.; Peterson, F.; Studt, F.; Abild-Pedersen, F.; Nørskov, J.K. Structure effects on the energetics of the electrochemical reduction of $\mathrm{CO}_{2}$ by copper surfaces. Surf. Sci. 2011, 605, 1254-1359. [CrossRef]

44. Schouten, K.J.P.; Kwon, Y.; van der Ham, C.J.M.; Qim, Z.; Koper, M.T.M. An new mechanism for the selectivity to $C_{1}$ and $C_{2}$ species in the electrochemical reduction of carbon dioxide on copper electrodes. Chem. Sci. 2011, 2, 1902-1909. [CrossRef]

45. Kortlever, R.; Shen, J.; Schouten, K.J.P.; Calle-Vallejo, F.; Koper, M.T.M. Catalysts and Reaction Pathways for the Electrochemical Reduction of Carbon Dioxide. J. Phys. Chem. Lett. 2015, 6, 4073-4082. [CrossRef] [PubMed]

46. Calle-Vallejo, F.; Koper, M.T.M. Theoretical Conciderations on the Electroreduction of CO to $\mathrm{C}_{2}$ Species on $\mathrm{Cu}(100)$ Electrodes. Angew. Chem. Int. Ed. 2013, 52, 7282-7285. [CrossRef] [PubMed]

47. Nie, X.; Esopi, M.R.; Janik, M.J.; Asthagiri, A. Selectivity of $\mathrm{CO}_{2}$ Reduction on Copper Electrodes: The Role of the Kinetics of Elemetentary Steps. Angew. Chem. Int. Ed. 2013, 52, 2459-2462. [CrossRef] [PubMed]

48. Ren, D.; Deng, Y.; Handoko, A.D.; Chem, C.S.; Malkhandi, S.; Yeo, B.S. Selective Electrochemical Reduction of Carbon Dioxide to Ethylene and Ethanol of Copper(I)Oxide Catalysts. ACS Catal. 2015, 5, 2814-2821. [CrossRef]

49. Kim, D.; Lee, S.; Ocon, J.D.; Jeong, B.; Lee, J.K.; Lee, J. Insights into an autonomously formed oxygen-evacuated $\mathrm{Cu}_{2} \mathrm{O}$ electrode for the selective production of $\mathrm{C}_{2} \mathrm{H}_{4}$ from $\mathrm{CO}_{2}$. Phys. Chem. Chem. Phys. 2015, 17, 824-830. [CrossRef] [PubMed]

50. Schouten, K.J.P.; Qin, Z.; Gallent, E.P.; Koper, M.T.M. Two Pathways for the formation of Ethylene in CO Reduction on Single-Crystal Copper Electrodes. J. Am. Chem. Soc. 2012, 134, 9864-9867. [CrossRef] [PubMed] 
51. Tang, W.; Peterson, A.A.; Varela, A.S.; Jovanov, Z.P.; Bech, L.; Durand, W.J.; Dahl, S.; Nørskov, J.K.; Chrokendorff, I. The importance of surface morphology in contolling the selectivity of polycrystalline copper for $\mathrm{CO}_{2}$ electroreduction. Phys. Chem. Chem. Phys. 2012, 14, 76-81. [CrossRef] [PubMed]

52. Bertheussen, E.; Verdaguer-Casadevall, A.; Ravasio, D.; Montoya, J.H.; Trimarco, D.B.; Roy, C.; Meier, S.; Wendland, J.; Nørskov, J.K.; Stephens, I.E.L.; et al. Acetaldehyde as an intermediate in the Electroreduction of Carbon Monoxide to Ethanol on Oxide-Derived Copper. Angew. Chem. Int. Ed. 2016, 55, 1450-1454. [CrossRef] [PubMed]

53. Reller, C.; Krause, R.K.; Neubauer, S.S.; Schmid, G.; Fleischer, M. $\mathrm{CO}_{2}$-to-value direct electrocatalytic reduction of $\mathrm{CO}_{2}$ towards chemical feedstock. In Proceedings of the 48 Jahrestreffen Deutscher Katalytiker, Congress Centrum Neue Weimarhalle, Weimar, Germany, 11-13 March 2015.

54. Reller, C.; Krause, R.; Volkova, E.; Schmid, B.; Neubauer, S.; Rucki, A.; Schuster, M.; Schmid, G. Selective Electroreduction of $\mathrm{CO}_{2}$ toward Ethylene on Nano Dendritic Copper Catalysts at High Current Density. Adv. Energy Mater. 2017. [CrossRef]

55. Kim, Y.-G.; Javier, A.; Baricuatro, J.H.; Soriaga, M.P. Regulating the Product Distribution of CO Reduction by the Atomic Level Structural Modification of the Cu Electrode Surface. Electrocatalysis 2016, 7, 391-399. [CrossRef]

56. Zinola, C.F. Electrocatalyis: Computational, Experimental and Industrial Aspects; CRC Press: Boca Raton, FL, USA, 2010; ISBN 978142004544.

57. Ma, S.; Sadakiyo, M.; Luo, R.; Heima, M.; Yamauchi, M.; Kenis, P.J.A. One-step electrosynthesis of ethylene and ethanol from $\mathrm{CO}_{2}$ in an alkaline electrolyzer. J. Power Sources 2016, 301, 219-228. [CrossRef]

58. Li, C.W.; Ciston, J.; Kanan, M.W. Electroreduction of Carbon Monoxide to Liquid Fuels on Oxide-Derived Nanocrystalline Copper. Nature 2014, 508, 504-520. [CrossRef] [PubMed]

59. Wesselbaum, S.; Moha, V.; Meuresch, M.; Brosinski, S.; Thenert, K.M.; vom Stein, T.; Englert, U.; Hölscher, M.; Klankermeyer, J.; Leitner, W. Hydrogenation of carbon dioxide to methanol using a homogeneous ruthenium-Triphos catalyst: From mechanistic investigations to multiphase catalysis. Chem. Sci. 2015, 6, 693-704. [CrossRef]

60. Murata, Y.; Hori, Y. Product Selectivity Affected by Cationic Species in Electrochemical Reduction of $\mathrm{CO}_{2}$ and $\mathrm{CO}$ at a Cu Electrode. Bull. Chem. Soc. Jpn. 1991, 64, 123-127. [CrossRef]

61. Wuttig, A.; Liu, C.; Peng, Q.; Yaguchi, M.; Hendon, C.H.; Motobayashi, K.; Ye, S.; Osawa, M.; Surendranath, Y. Tracking a Common Surface-Bound Intermediate during $\mathrm{CO}_{2}$-to-Fuels Catalysis. ACS Cent. Sci. 2016, 2, 522-528. [CrossRef] [PubMed]

62. Ledezma-Yanes, I.; Pérez Gallent, E.; Koper, M.T.M.; Calle-Vallejo, F. Structure-sensitive electroreduction of acetaldehyde to ethanol on copper and its mechanistic implications for $\mathrm{CO}$ and $\mathrm{CO}_{2}$ reduction. Catal. Today 2016, 262, 90-94. [CrossRef]

63. Loeffler, K.W.; Koehler, C.A.; Paul, N.M.; De Haan, D.O. Oligomer formation in evaporating aqueous glyoxal and methyl glyocal solutions. Environ. Sci. Technol. 2006, 40, 6318-6323. [CrossRef] [PubMed]

64. Gupta, N.; Gattrell, M.; MacDougall, B. Calculations for the cathode surface concentrations in the electrochemical reduction of $\mathrm{CO}_{2}$ in $\mathrm{KHCO}_{3}$ solutions. J. Appl. Electrochem. 2006, 36, 161-172. [CrossRef]

65. Montoya, J.H.; Peterson, A.A.; Nørskov, J.K. Insights into C-C coupling in $\mathrm{CO}_{2}$ Electroreduction on Copper Electrodes. ChemCatChem 2013, 5, 737-742. [CrossRef]

66. Kropp, K.; Skibbe, V.; Erker, G.; Krueger, C. Fischer-Tropsch intermediates: Tris[(.eta.2-formaldehyde) zirconocene] from the carbonylation of a zirconium hydride. J. Am. Chem. Soc. 1983, 105, 3353-3354. [CrossRef]

67. Suess, D.L.M.; Peters, J.C. A CO-Derived Iron Dicarbyne That Releases Olefin upon Hydrogenation. J. Am. Chem. Soc. 2013, 135, 12580-12583. [CrossRef] [PubMed]

68. Song, X.; Du, H.; Liang, Z.; Zhu, Z.; Duan, D.; Liu, S. Paired Electrochemical Synthesis of Ethylene and Oxalic Acid from Acetylene. Int. J. Electrochem. Sci. 2013, 8, 6566-6573.

69. Rüchardt, C.; Schrauzer, G.N. Über die Carbonylierung von Carbenen und die katalytische Zersetzung von Diazoalkanen mit Nickeltetracarbonyl. Chem. Ber. 1960, 93, 1840-1848. [CrossRef]

70. Mankad, N.P.; Peters, J.C. Diazoalkanes react with a bis(phosphino)borate copper(I) source to generate $\left[\mathrm{Ph}_{2} \mathrm{BP}^{\mathrm{tbu}}{ }_{2}\right] \mathrm{Cu}\left(\eta^{1}-\mathrm{N}_{2} \mathrm{CR}_{2}\right),\left[\mathrm{Ph}_{2} \mathrm{BP}^{\mathrm{tBu}}{ }_{2}\right] \mathrm{Cu}\left(\mathrm{CPh}_{2}\right)$, and $\left[\mathrm{Ph}_{2} \mathrm{BP}^{\mathrm{tbu}}{ }_{2}\right] \mathrm{Cu}-\mathrm{N}\left(\mathrm{CPh}_{2}\right)\left(\mathrm{NCPh}_{2}\right)$. Chem. Commun. 2008, 1061-1063. [CrossRef] [PubMed] 
71. Dai, X.; Warren, T.H. Discrete Bridging and Terminal Copper Carbenes in Copper-Catalyzed Cyclopropanation. J. Am. Chem. Soc. 2004, 126, 10085-10094. [CrossRef] [PubMed]

72. Grotjahn, D.B.; Bikzhanova, G.B.; Collins, L.S.B.; Concolino, T.; Lam, K.-C.; Rheingold, A.L. Controlled, Reversible Conversion of a Ketene Ligand to Carbene and CO Ligands on a Single Metal Center. J. Am. Chem. Soc. 2000, 122, 5222-5223. [CrossRef]

73. Bodnar, T.W.; Cutler, A.R. Formation of a stable (.eta.2-C,C) ketene compound dicarbonyl(cyclopentadienyl) keteneiron hexafluorophosphate $\left[\left(\mathrm{C}_{5} \mathrm{H}_{5}\right) \mathrm{Fe}(\mathrm{CO})_{2}(\mathrm{CH} 2 \mathrm{CO})^{+} \mathrm{PF}_{6}{ }^{-}\right]$by carbonylation of an iron methylidene complex. A novel entry into carbonyl-derived C2 chemistry. J. Am. Chem. Soc. 1983, 105, 5926-5928. [CrossRef]

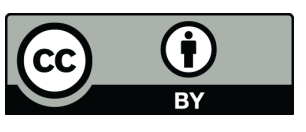

(C) 2017 by the authors. Licensee MDPI, Basel, Switzerland. This article is an open access article distributed under the terms and conditions of the Creative Commons Attribution (CC BY) license (http:/ / creativecommons.org/licenses/by/4.0/). 